\title{
ПОКАЗАТЕЛИ ИММУННОЙ СИСТЕМЫ У ПОДРОСТКОВ С ОСТЕОАРТРОЗОМ НА ФОНЕ ГИПЕРМОБИЛЬНОГО СИНДРОМА
}

\author{
(С Матвиенко Е.В., Хмелевская И.Г., Двойных Н.Д., Разинькова Н.С.
}

\author{
Кафедра педиатрии Курского государственного медицинского университета, Курск \\ E-mail: dvoinyh.nina@yandex.ru
}

\begin{abstract}
Изучены показатели иммунологического гомеостаза у 84 подростков 12-18 лет с остеоартрозом (ОА) на фоне гипермобильности суставов (ГМС). Группу сравнения составили подростки идентичного возраста с остеоартрозом без гипермобильности суставов. Установлены значительные изменения в иммунной системе, которые характеризовались нарушениями в различных звеньях иммунитета и проявлялись депрессией моноцитарно-фагоцитарной системы Т-звена, умеренной активацией В-звена, дисглобулинемиями, повышением комплимента. Более значительные отклонения показателей наблюдались у больных с остеоартрозом и гипермобильностью суставов одновременно и нарастали со степенью увеличения гипермобильности суставов. Определено увеличение иммунологических расстройств у пациентов с ростом степени мобильности суставов.
\end{abstract}

Ключевые слова: подростки, остеоартроз, гипермобильность суставов, иммунная система.

\section{INDICATORS OF THE IMMUNE SYSTEM IN ADOLESCENTS WITH OSTEOARTHRITIS AGAINST THE BACKGROUND OF HYPERMOBILE SYNDROME \\ Matvienko E.V., Khmelevskaya I.G., Dvoynykh N.D., Razinkova N.S. \\ Department of Pediatrics of Kursk State Medical University, Kursk}

Indicators of an immunological homeostasis in 84 adolescents aged 12-18 years with osteoarthrosis (OA) against the background of hyper mobility of joints (GMS) are studied. The group of comparison was made by adolescents of identical age with osteoarthrosis without hyper mobility of joints. The considerable changes in the immune system which were characterized by disturbances in various links of immunity and manifested themselves by the depression of monocyte- phagocytic system of the T-link, the moderate activation of the V-link, dysglobulinemia, and compliment increase were established. More considerable deviations of indicators were observed in patients with osteoarthrosis and simultaneous hyper mobility of joints and accrued with the extent of increase in hyper mobility of joints. Increase in immunological frustration in patients with growth of joint mobility degree was defined.

Keywords: adolescents, osteoarthrosis, hypermobility syndrome, immune system.

Поражения опорно-двигательного аппарата относятся к наиболее распространенной патологии, среди которой особую значимость имеет остеоартроз (ОА). ОА представляет собой как общемедицинскую, так и социально-экономическую проблему, характеризуется развитием функциональных нарушений в суставах, потерей работоспособности, инвалидизацией больных и, тем самым, снижением качества их жизни, значительными финансовыми затратами [2, 3].

Проблема ОА в течение нескольких десятилетий активно разрабатывается у взрослых. Существует мнение, что эта патология характерна для людей зрелого и пожилого возраста. Значительные достижения, полученные в последнее время в изучении ОА у взрослых, касаются в основном развернутых стадий болезни, но важным для диагностики, своевременного назначения адекватного лечения является определение ранних проявлений ОА и механизмов его развития на начальных этапах становления [4].

Актуальность проблемы возрастает в связи с тем, что в последние годы ОА не только распространяется среди населения, но и нередко дебю- тирует в более молодом возрасте у подростков. По данным отдельных исследователей, начало болезни у потомков происходит на 20 лет раньше, чем у родителей $[5,6,7]$.

В наше время определенное внимание исследователей уделяется также проблеме дисплазии соединительной ткани (СТ), в основе развития которой значительная роль отводится генетически детерминированному дефекту синтеза и метаболизма фибриллярных структур. К частым проявлениям дисплазии СТ относится гипермобильный синдром (ГМС) [9, 10].

Как известно, в патогенезе ОА ведущее место отводится изменениям в метаболизме соединительной ткани, что подтверждается перераспределением фракций гликозаминогликанов в сыворотке крови, увеличением уровня хондроитинсульфатов, а также экскреции уроновых кислот и оксипролина [4]. Определены у больных ОА отклонения и в иммунной системе, что доказано исследованиями у взрослых [8]. Установлено, что при поражении значительного количества суставов иммунологические изменения имеют важное патогенетическое значение и проявляются имму- 
нологической депрессией, прежде всего, клеточного иммунитета, фагоцитоза [11-13].

Успехи, достигнутые в последнее время в изучении патомеханизмов заболевания у взрослых, касаются развернутых стадий со значительными клинико-рентгенологическими признаками, но важным для ранней диагностики и своевременного назначения лечения является установление главных звеньев патогенеза на начальных этапах становления ОА.

Определение особенностей иммунологического гомеостаза при ОА у подростков на фоне ГМС, обладающего своеобразием метаболизма соединительной ткани, что влияет на функциональную активность иммунной системы, позволит, возможно, объяснить более частое развитие дегенеративных изменений в суставах уже в молодом возрасте, создаст реальные предпосылки для разработки рациональных схем лечения, предотвращения прогрессирования заболевания. Непосредственное отношение это имеет к подростковому возрасту, учитывая увеличение частоты болезни в данном возрастном периоде.

Цель исследования - уточнение отклонений в показателях иммунной системы у подростков, больных остеоартрозом, развившемся на фоне гипермобильного синдрома.

\section{МАТЕРИАЛЫ И МЕТОДЫ ИССЛЕДОВАНИЯ}

В клинике было обследовано 82 подростка 12-18 лет, больных ОА и ГМС одновременно. Среди них было 32 юноши и 50 девушек. Согласно критериям диагностики ГМС С. Carter и J. Wilkinson в модификации P. Beigthon, которые включали балльный счет выполнения четырех парных и одного непарного движения, пациенты распределялись на две группы. В первую группу вошли 24 подростка с легкой степенью гипермобильности суставов, среди них 14 юношей и 10 девушек; во вторую - 58 больных с выраженной степенью ГМС (соответственно 18 и 40). Группа сравнения включала 24 подростка идентичного возраста с остеоартрозом без наличия ГМС (лиц мужского пола - 20, женского - 4).

Для установления диагноза использовали современную классификацию ревматических заболеваний.

Иммунологическое исследование включало определение в клеточном звене иммунитета популяций и субпопуляций лимфоцитов Т-хелперов (CD4+), Т-супрессоров (CD8+), Т-общих лимфоцитов (CD3+), В-лимфоцитов $(\mathrm{CD} 19+)$ с помощью метода мембранной иммунофлюоресценции с моноклональными антителами, Т-активных лимфоцитов - методом розетко- образования по P.J. Felsburg et al. Уровень сывороточных иммуноглобулинов (Ig) классов $\mathrm{A}, \mathrm{M}, \mathrm{G}$ определяли спектрофотометрическим методом, концентрацию иммунных комплексов (ЦИК) скрининг-тестом, уровень комплемента - методом Chudomels в модификации Кондрашовой. Состояние моноцитарно-фагоцитарного звена иммунитета оценивали путем определения фагоцитарного числа (Фч), фагоцитарного индекса $(Ф и)$, спонтанного и индуцированного НСТ-теста [1].

Статистическую обработку данных выполняли с помощью пакета программ STATGRAPHICS plus 5.1. Результаты исследования приведены как средний показатель со стандартным отклонением от среднего $(\mathrm{M} \pm \mathrm{m})$ и частоты отклонения показателей. Для определения достоверности показателей использован метод углового преобразователя Фишера и $\mathrm{t}$-критерий Стьюдента.

\section{РЕЗУЛЬТАТЫ ИССЛЕДОВАНИЯ И ИХ ОБСУЖДЕНИЕ}

Результаты полученных исследований позволили выявить нарушения в клеточном звене иммунитета, которые характеризовались его депрессией, в основном, за счет достоверного снижения общего числа Т-клеток и хелперно-супрессорной субпопуляции $(\mathrm{p}<0,001)$. Причем снижение общих Т-лимфоцитов имело место у $84,5 \%$ подростков, а повышение уровня Т-активных клеток - практически у половины больных $(47,6 \%)$. Изменения иммунорегуляторных субпопуляций лимфоцитов характеризовались более значительным снижением Т-супрессоров / цитотоксических по отношению к Т-хелперам ( $<<0,01)$, что наблюдалось у подавляющего большинства подростков. Наряду с этим определено увеличение иммунорегуляторного индекса (Т-х / Т-c), который обнаружен у $66,2 \%$ обследуемых, что, в целом, очевидно, свидетельствовало о значимости аутоиммунных процессов в формировании заболевания. Следует указать, что более значительные отклонения в показателях наблюдались у подростков на фоне выраженной гипермобильности суставов.

В таблице 1 указаны иммунологические показатели у больных остеоартрозом на фоне гипермобильного синдома. По данным средних значений как в общей группе больных, так и у подростков с разной степенью выраженности ГМС, получены доказательства активации В-клеточного звена иммунитета. Выявлено увеличение количества В-лимфоцитов ( $<0,001)$, комплемента, циркулирующих иммунных комплексов, концентрации иммуноглобулина А $(\mathrm{p}<0,001)$. 
Таблица 1

Иммунологические показатели у подростков, больных остеоартрозом, на фоне гипермобильного синдрома в зависимости от его степени и пола $(\mathrm{M} \pm \mathrm{m})$

\begin{tabular}{|c|c|c|c|c|c|c|}
\hline \multirow[t]{3}{*}{ Показатели } & \multirow[t]{3}{*}{ Всего $(n=84)$} & \multicolumn{4}{|c|}{ Степень гипермобильного синдрома } & \multirow{3}{*}{$\begin{array}{c}\text { Здоровые } \\
(\mathrm{n}=23)\end{array}$} \\
\hline & & \multicolumn{2}{|c|}{ легкая } & \multicolumn{2}{|c|}{ выраженная } & \\
\hline & & $\begin{array}{c}\text { девушки } \\
(\mathrm{n}=10)\end{array}$ & юноши $(n=14)$ & $\begin{array}{c}\text { девушки } \\
(\mathrm{n}=37)\end{array}$ & юноши $(\mathrm{n}=18)$ & \\
\hline $\mathrm{CD} 3+, \%$ & $43,35 \pm 1,20 * * *$ & $42,00 \pm 4,91 * * *$ & $43,75 \pm 2,52 * * *$ & $42,50 \pm 2,07 * * *$ & $45,00 \pm 2,42 * * *$ & $57,60 \pm 1,42$ \\
\hline Т-акт.л., $\%$ & $32,48 \pm 0,71$ & $33,75 \pm 2,46$ & $33,00 \pm 1,65$ & $1,31 \pm 1,42$ & $33,15 \pm 1,13$ & $31,10 \pm 0,81$ \\
\hline CD19+,\% & $24,11 \pm 0,45 * * *$ & $24,75 \pm 1,49 * * *$ & $24,75 \pm 0,75^{* * *}$ & $24,75 \pm 1,08^{* * *}$ & $23,23 \pm 0,48^{* * *}$ & $21,00 \pm 0,43$ \\
\hline $\mathrm{CD} 4+, \%$ & $33,60 \pm 1,02 * * *$ & $35,5 \pm 5,23$ & $33,37 \pm 1,75^{* * *}$ & $32,00 \pm 1,77 * * *$ & $35,76 \pm 1,98^{* *}$ & $41,73 \pm 1,20$ \\
\hline $\mathrm{CD} 8+, \%$ & $10,16 \pm 1,10$ & $6,5 \pm 0,95 * * *$ & $10,37 \pm 1,81$ & $10,5 \pm 1,51$ & $9,23 \pm 1,13 * * *$ & $13,8 \pm 0,9$ \\
\hline $\begin{array}{l}\text { CD4+/ } \\
\text { CD8+ }\end{array}$ & $4,44 \pm 0,65$ & $5,91 \pm 1,27$ & $4,13 \pm 0,82$ & $4,95 \pm 1,12$ & $4,81 \pm 0,75$ & $3,1 \pm 1,0$ \\
\hline Фч, \% & $63,31 \pm 1,94 * * *$ & $65,50 \pm 4,62 * *$ & $61,75 \pm 3,18^{* * *}$ & $63,87 \pm 2,62 * * *$ & $66,69 \pm 3,23 * * *$ & $78,01 \pm 0,51$ \\
\hline Фи, абс. & $5,70 \pm 0,41 * * *$ & $5,32 \pm 0,22 * * *$ & $4,92 \pm 0,34 * * *$ & $5,6 \pm 0,18 * * *$ & $5,24 \pm 0,22 * * *$ & $7,31 \pm 0,22$ \\
\hline НСТ-сп., \% & $24,42 \pm 1,30 * * *$ & $27,75 \pm 2,09 * * *$ & $23,87 \pm 1,60 * * *$ & $21,93 \pm 0,93 * * *$ & $23,76 \pm 1,92 * * *$ & $11,20 \pm 0,53$ \\
\hline НСТ-ин., \% & $32,10 \pm 1,18^{* * *}$ & $38,5 \pm 2,90 * * *$ & $33,75 \pm 2,67 * * *$ & $32,18 \pm 1,78^{* * *}$ & $30,92 \pm 1,99 * * *$ & $20,60 \pm 0,82$ \\
\hline IgA, Г/л & $2,54 \pm 0,32 * * *$ & $2,57 \pm 0,72$ & $2,76 \pm 0,44 * *$ & $2,99 \pm 0,78^{*}$ & $2,22 \pm 0,29$ & $1,50 \pm 0,11$ \\
\hline IgM, Г/л & $1,45 \pm 0,06$ & $1,55 \pm 0,52$ & $1,58 \pm 0,17$ & $1,44 \pm 0,11$ & $1,47 \pm 0,17$ & $1,50 \pm 0,21$ \\
\hline $\mathrm{IgG}$, г/л & $13,68 \pm 0,57$ & $15,30 \pm 1,97$ & $14,52 \pm 1,13^{*}$ & $14,17 \pm 0,81$ & $12,49 \pm 1,83$ & $12,30 \pm 0,72$ \\
\hline ЦИК, г/л & $1,12 \pm 0,07$ & $1,13 \pm 0,13$ & $0,72 \pm 0,08$ & $1,40 \pm 0,14$ & $0,74 \pm 0,09$ & $0,94 \pm 0,12$ \\
\hline $\begin{array}{c}\text { Компле- } \\
\text { мент, ус.ед. }\end{array}$ & $1,27 \pm 0,03$ & $1,09 \pm 0,08$ & $1,15 \pm 0,04$ & $1,35 \pm 0,09$ & $1,35 \pm 0,11$ & $1,20 \pm 0,14$ \\
\hline
\end{tabular}

Примечание: * - достоверность отличий показателей по критерию Стьюдента относительно здоровых при $\mathrm{p}<0,02 ; * *-\mathrm{p}<0,01$; $* * *-\mathrm{p}<0,001$.

Активация гуморального звена иммунитета выявлялась и по данным частоты отклонений показателей. Так, повышение уровня $\mathrm{CD} 19^{+}$определен у $32,8 \%$ больных, дисиммуноглобулинемия с четким увеличением содержания IgA отмечалась у 58,5\% подростков, установлено также повышение $\operatorname{IgG}(23,5 \%), \operatorname{IgM}(8,7 \%)$. Достоверно более высокий уровень ЦИК и комплемента наблюдался почти у $1 / 3$ больных.

Во всех группах пациентов оказалась значительно сниженной фагоцитарная активность нейтрофилов, что подтверждалось уменьшением фагоцитарного числа и фагоцитарного индекса $(\mathrm{p}<0,001)$, которые были достоверно ниже у подростков, больных ОА на фоне выраженной гипермобильности суставов. Депрессия моноцитарно-фагоцитарного звена иммунитета характеризовалась снижением фагоцитарного числа у $73,5 \%$ больных и фагоцитарного индекса - почти у $2 / 3$ пациентов. Наряду с этим рост показателей НСТ-тестов, спонтанного и индуцированного $(\mathrm{p}<0,001)$, свидетельствовал о повышении антигенной нагрузки на организм и уменьшении поглощающей способности клеток этого звена иммунитета.

На основании проведенных исследований не выявлено различий средних значений показателей в зависимости от пола больных. Однако установлены более глубокие нарушения в иммунном ста- тусе больных 12-18 лет при увеличении длительности заболевания более 4 лет и накопления нескольких клинико-рентгенологических признаков, указывающих на развитие дегенеративных изменений в суставном хряще.

Сравнительный анализ данных у подростков в зависимости от степени ГМС и при ее отсутствии обнаружил четкую тенденцию к увеличению иммунологических отклонений у больных остеоартрозом, который формировался на фоне гипермобильности, и прямо пропорциональную связь повышения этих нарушений со степенью выраженности мобильности суставов $(\mathrm{p}<0,05)$.

У подростков с ОА, развившемся на фоне гипермобильности суставов, определяются нарушения в различных звеньях иммунитета, которые проявляются депрессией Т-клеточного звена, моноцитарно-фагоцитарной системы, умеренной активацией В-звена иммунитета. Установленные закономерности, вероятно, указывают на аутоиммунный характер воспаления.

Доказано, что более значительные отклонения показателей иммунной системы наблюдаются у больных ОА и ГМС одновременно по сравнению с ОА, у которых ГМС отсутствует. Определено увеличение иммунологических расстройств у пациентов с ростом степени мобильности суставов. 


\section{ЛИТЕРАТУРА}

1. Иммунология в клинической практике: учебник. 1-е изд. / под ред. Лебедева К.А. - М. : Медицина, 1996. $-387 \mathrm{c}$.

2. Коваленко В.Н., Борткевич О.П. Остеоартроз: практическое руководство. - Киев : Морион, 2003. $-448 \mathrm{c}$.

3. Лебеи И.С., Шевченко Н.С., Матвиенко Е.В. Прогнозирование прогрессирования остеоартроза у подростков // Таврический медико-биологический вестник. - 2011. - Т. 4, № 2. - С. 160-161.

4. Лебеи И.С., Матвиенко Е.В., Костюрина Н.А., Нелина И.Н. Остеоартроз и гипермобильность суставов // Травма. - 2005. - Т. 6, № 3. - С. 262-266.

5. Матвиенко E.B. Характеристика показателей иммунной системы у подростков, больных остеоартрозом, на фоне гипермобильного синдрома // Педиатрия, акушерство и гинекология. - 2006. № 1. - C. 36-38.

6. Пилипович A.A. Остеоартроз: патогенетические и терапевтические аспекты // Российский медицинский журнал. - 2016. - № 7. - С. 464-468.

7. Шевченко Н.С., Лебеи И.С., Матвиенко Е.В. Ведущие механизмы формирования остеоартроза у подростков и обоснование их лечения // Современная педиатрия. - 2008. - № 2. - С. 130-134.
8. Шевченко Н.С., Лебеи И.С., Матвиенко Е.В. Патогенетическое значение воспаления при остеоартрозе у подростков с инициальными стадиями заболевания // Украинский ревматологический журнал. - 2010. - № 1 (39). - С. 50-54.

9. Шостак Н.А. Остеоартроз: актуальные вопросы диагностики и лечения // Российский медицинский журнал. - 2014. - № 4. - С. 278-280.

10. Шостак Н.А., Правдюк Н.Г., Магомедова Д.Н. Гипермобильный синдром: клиника, диагностика, подходы к терапии // Российский медицинский журнал. - 2009. - № 4. - С. 288-290.

11. Kobayashi M., Squires G.R., Mousa A., Tanzer M., Zukor D.J., Antoniou J., Feige U., Poole A.R. Role of interleukin-1 and tumor necrosis factor alpha in matrix degradation of human osteoarthritic cartilage // Arthritis Rheum. - 2005. - Vol. 52, N 1. - P. 128-135. doi: 10.1002/art.20776

12. Sakkas, L.S., Platsoucas C.D. The role of T cells in the pathogenesis of osteoarthritis // Arthritis Rheum. 2007. - Vol. 56, N 2. - P. 409-424. - doi: $10.1002 /$ art.22369

13. Takayanagi $H$. Inflammatory bone destruction and osteoimmunology // J Periodontal Res. - 2005. Vol. 40, N 4. - P. 287-293. 